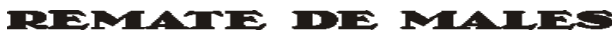

Campinas-SP, v. 38, n. 1, pp. 54-62, jan./jun. 2018

\title{
OS ESTUDOS SOBRE GOA NO ÂMBITO DO OCEANO ÍNDICO
}

\author{
Joana Passos
}

\begin{abstract}
Resumo: Durante décadas, Goa era um assunto esquecido ou marginal nos estudos que procuraram rever a história colonial e mapear os desenvolvimentos da descolonização europeia. Mas, na transição para o século XXI, Goa tornou-se o objecto de estudo de vários projectos de investigação e é temática cada vez mais conhecida. Por quê? E o que se tem concluído de diversos estudos sobre esse pequeno mas intrigante estado? A minha contribuição pretende oferecer uma visão do estado da arte relativa aos estudos sobre Goa, sublinhando as principais conclusões e o interesse dessas mesmas conclusões para os estudos sobre as dinâmicas sociopolíticas e culturais do Oceano Índico. Em segundo lugar, e dada a existência de várias línguas oficiais em Goa (konkani, marata e inglês), qual o lugar da herança cultural portuguesa e qual é o actual enquadramento dos estudos da literatura goesa em língua portuguesa?

Palavras-chave: tradução; rotas migratórias; memória histórica na literatura.
\end{abstract}

Quando há cerca de quinze anos me debrucei pela primeira vez sobre a literatura de Goa em língua portuguesa, verifiquei que, no caso específico da academia portuguesa, os estudos literários encaravam Goa como objecto de interesse enquanto parte da história colonial de Portugal. No âmbito da história, a situação era semelhante, embora se distinguisse o grupo dos historiadores de arte que se centravam no rico espólio da chamada arte sacra indo-portuguesa. Esse subgrupo de pensadores já considerava a arte de Goa como um corpus particular e específico, digno de um estudo que não se limitava a ilustrar uma faceta do passado colonial português. Outra interessante excepção eram os antropólogos como Rosa Peres, ou etnomusicólogos como Sandra Sardo, sem esquecer os estudos

1 Investigadora doutorada, CEHUM - Centro de Estudos Humanísticos da Universidade do Minho, Portugal: JPassos@ilch.uminho.pt. 
de Cristiana Bastos sobre a escola médica de Goa. Gradualmente, o debate académico começou a debruçar-se sobre as realidades goesas em si, tentando promover uma melhor compreensão dessa sociedade e de suas culturas locais ao nível internacional. Em suma, quanto à definição de campos de estudo, passamos da percepção de Goa, e das relações com a Índia, como foco de interesse enquanto uma "parte" dos estudos de Portugal sobre si próprio, para um diálogo académico internacional, em que participam outros estudiosos europeus e indianos. Em Portugal também existe maior consciência de que a relação com Goa é uma longa história, marcada por tensões e conflitos, e não só como palco de trocas comerciais, influências mútuas e privilegiadas rotas na deslocação de pessoas e bens.

Mesmo assim, as questões literárias ficavam na zona de sombra dos debates académicos vigentes. Quanto aos críticos literários que se empenharam em estudar as chamadas "literaturas lusófonas" (as quais só mais tarde passaram a ser "literaturas de expressão portuguesa" e, posteriormente, "literaturas de língua portuguesa", dado que o que é partilhado é a língua, e não a expressão de culturas e identidades), fizeram-no no âmbito dos estudos pós-coloniais em Portugal, e olhavam sobretudo para África, onde vários países tinham literaturas nacionais de língua portuguesa, o que não acontecia com Goa.

Ou seja, fosse por estar à margem dos campos disciplinares dominantes, ou por se tratar de uma literatura com um futuro incerto (em temos de língua portuguesa), a literatura de Goa, como objecto de estudo, acabava por ficar, comparativamente, em segundo plano.

Em 2013, a revista Portuguese Literary \& Cultural Studies (da Universidade de Massachusetts Dartmouth), publicou um número sobre a relevância e utilização do conceito "lusofonia", reconhecendo a polémica em torno do termo, nomeadamente, pela implícita invocação de uma lógica imperial hierarquizante, que delineava várias margens, a partir de um suposto centro luso. Na altura, em conjunto com um grupo de colegas que trabalhavam sobre Goa, decidimos escrever um artigo colectivo, publicado nesse número da revista, ${ }^{2}$ que, mais do que confrontar o termo "lusofonia" em si, confrontava os limites impostos pelo mapeamento proposto pelos estudos lusófonos. A questão que colocávamos era se, pelo facto de o português já não ser uma das línguas oficiais de Goa

2 Passos et al. (2013). 
(encontrando-se em declínio o número de falantes de português nesse território), a herança cultural resultante da colonização portuguesa por um período de quatro séculos, em Goa, já não parecia ter relevância no campo dos estudos que então reflectia sobre as escritas de língua portuguesa, por diversas geografias. Na altura, eu própria havia publicado recentemente a minha proposta para uma história literária de Goa em língua portuguesa $(\mathbf{2 0 1 2})^{3}$ e concluí esse projecto com o sentimento de que estava a rever a memória de um espólio que possivelmente iria ficar esquecido, mas que, mesmo assim, não deveria ficar representado nos arquivos académicos e históricos por uma visão portuguesa que ainda não havia desconstruído os seus preconceitos coloniais, exacerbados pela vertente fascista da fase final da história colonial portuguesa. Era preciso reconhecer e valorizar a resistência goesa ao colonialismo, os debates que haviam ocorrido no terreno e cuja diversidade era geralmente obliterada, e, por fim, era preciso valorizar a mestiçagem cultural e as fusões estéticas ensaiadas pelos autores locais. Todas essas vertentes escapavam a uma visão eurocêntrica (colonial) e egocêntrica (moldada por redutores interesses nacionalistas), que então ainda era dominante em certos sectores da academia portuguesa.

Hoje em dia, pelo contrário, a produção literária de Goa tem conquistado o reconhecimento da sua singularidade, enquanto objecto de estudo incluído em várias conferências, em Goa, em Portugal, no Reino Unido e no Brasil.

Auspiciosa e marcante foi uma conferência em Goa, em 2011, intitulada "Goa: 1961 and Beyond", organizada pelo Indian Institute of Advanced Study - Shimla, pela Goa University e pelo Centro de Estudos Sociais (Coimbra), na Universidade de Goa, compreendendo um amplo leque de disciplinas (além das acima referidas, destacaria o direito e a arquitectura). Essa conferência relançou a preponderância de Goa para vários campos de estudo, em nível internacional (envolvendo investigadores dos mais variados países). Também por ser em Goa e envolver a academia indiana, a conferência teve o mérito de encorajar posteriores estudos, revelando abertura e empenho relativamente ao estudo da herança cultural de Goa por parte da complexa e plural rede que é a academia indiana.

Em Portugal, destacaria a publicação do dossier "Narrando o Índico" (Diacrítica - Série Estudos Literários, v. 27, n. 3, 2013), por ser uma das 
primeiras a explorar a inclusão de Goa nos estudos do Oceano Índico, bem como os livros Goa portuguesa e pós-colonial: literatura, cultura e sociedade, com organização de Everton Machado e Duarte D. Braga (2014), e Goa passado e presente (MATOS; CUNHA, 2012), publicações que demonstram a centralidade de Goa como tema aglutinador do estudo de vários investigadores, recolhendo os trabalhos de duas conferências organizadas, respectivamente, pelo Centro de Estudos Comparatistas (Universidade de Lisboa) e pela Universidade Católica (Lisboa). Esses eventos apontam, a meu ver, uma mudança nos estudos literários sobre Goa, em Portugal, mudança essa que se consolidou na sequência de tais eventos, por volta de 2013 e 2014.

Mais recentemente, referiria o projecto de investigação "Orientalismo português", coordenado por Everton Machado, e "Narrativas do Oceano Índico no Espaço Lusófono" (Nilus), sob coordenação da professora Ana Mafalda Leite, que aponta para um alargamento do quadro de referência nas abordagens a Goa, integrando-a nas dinâmicas regionais (culturais, históricas, políticas e estéticas) da zona onde está inserida. Essa viragem para estudos comparativos transnacionais, à margem do binómio colonial que sempre impunha um eixo comparativo colonizador/ colonizado, contraria práticas e padrões de investigação que partiam de uma visão eurocêntrica do mundo, regressando à história colonial como matriz interpretativa. Outro interessante desenvolvimento foi o recente congresso internacional sobre Política e Cultura na Imprensa Colonial, realizado em Lisboa (22 a 25 de maio, 2017, Universidade Nova de Lisboa), onde se verificou que a inclusão de Goa no mapa dos estudos sobre o período colonial promove uma plataforma comparativa Ásia/África ainda pouco explorada, respondendo de forma eficaz à questão que o grupo de estudiosos de Goa havia colocado no número citado acima sobre Lusofonia da Portuguese Literary \& Cultural Studies (2013), uma vez que Goa é incluída no mapeamento das várias publicações coloniais de língua portuguesa.

No Reino Unido, foi sobretudo a área dos estudos diplomáticos que suscitou o interesse sobre Goa, por ser um enclave, aninhado entre dois impérios, onde confluíam rivalidades culturais e religiosas e onde se jogou o arranque das lutas pela independência das colónias portuguesas em África. Isso porque Nheru procurou assumir um papel de líder mundial na libertação de outros povos colonizados, representando uma terceira via os países “não alinhados”, que nas décadas de 1960/1970 não queriam ficar 
dependentes dos blocos mundiais em confronto: o capitalismo americano e o comunismo soviético. E, de facto, a queda de Goa terá tido um impacto significativo em outros territórios colonizados por Portugal. Por fim, de um ponto de vista político, Goa levantou a questão da balcanização dos territórios descolonizados, visto que existiu uma vertente que pugnou pela autonomia de Goa, possibilidade que justifica o inicial esforço de Nova Delhi para diluir o estado de Goa ao incluí-lo no Maharasthra (Goa só se tornou um estado autónomo em 1987). Por todas essas razões, Goa interessou aos debates da Universidade de Nottingham ${ }^{4}$ (e ao seu polo na Malásia) ${ }^{5}$ por ser um ponto nodal, um excelente caso de estudo para ver como se cruzavam as ramificações do local e do global. Destacaria também o trabalho de Paul Melo e Castro (Universidade de Leeds), uma consolidada referência nos estudos literários sobre Goa.

No Brasil gostaria de salientar o ambicioso e produtivo projecto "Pensando Goa", coordenado pelo professor Helder Garmes, Universidade de S. Paulo. O objectivo desse estudo é "reescrever a história da literatura de língua portuguesa de Goa [...] privilegiando, por um lado, suas relações com as demais manifestações culturais, intelectuais e artísticas daquela sociedade e, por outro, as relações [...] entre essa literatura e outras [...]" (PENSANDO GOA, [s.d.], [s.p.]).

Também se verifica um crescente interesse na literatura goesa por parte da crítica indiana, sobretudo devido ao incremento na tradução dessa literatura em português para a língua inglesa, o que disponibilizou autores e obras a novos públicos. Se bem que vários autores goeses escrevessem em inglês - como por exemplo Joseph Furtado, goês que tem o estatuto fundador de ser o primeiro indiano a escrever poesia em inglês -, na verdade, a questão da tradução, em Goa, tem também outras vertentes interessantes. Se a literatura goesa em português parecia uma tradição literária destinada a extinguir-se, ao ser traduzida e publicada, ela se vê revitalizada e novamente estudada. Por outro lado, referências literárias que seriam exclusivas a Goa passam a circular por toda a Índia,

4 International Conference Enclaves North and South, organizada por International Consortium for the Study of Post-Conflict Reconstruction and Reconciliation, 23 mar. 2014, Nottingham University, UK. Recorde-se também o International Colloquium Lusofonias Verticais e Horizontes/ Lusophone Worlds: East-West/ North-South, 29-31 maio 2011, University of Nottingham, ocorrido três anos antes.

5 Colloquium The Indian Ocean - Terrains of Meaning and Materiality: Technology and Cultural Commerce, 8 maio 2014, University of Nottingham, Malasya, Campus Kuala Lumpur. 
facto que poderá ter implicações interessantes. Por exemplo, e a partir de uma perspectiva dos Estudos do Oceano Índico (que se centra nas trocas e cruzamentos culturais regionais, seja em nível intra-nacional, seja internacional) as referências a Moçambique na literatura goesa tornam-se um motivo literário que circula na Índia, via literatura goesa traduzida para o inglês. Paralelamente, as influências românticas e modernistas que também marcaram a literatura indiana de língua inglesa, encontram eco na tradição literária goesa, que seria uma das portas de entrada de modas literárias europeias no subcontinente indiano. Esse facto deverá encontrar lugar no mapa da difusão de ideias europeias pelo subcontinente indiano, contribuindo para tornar a vida cultural do subcontinente mais cosmopolita e actualizada. Inversamente, não é pequeno o serviço prestado pelos autores indianos e goeses à divulgação internacional das tradições, mitologias e história indianas, ao escreverem sobre esses temas. Tal contributo por autores goeses também se pode agora reconhecer por meio da apreciação crítica desses autores pela academia indiana, uma vez disponibilizado o texto em língua inglesa.

A propósito, sublinhe-se que a tradução da literatura goesa em português não é um facto isolado. Segue, isso sim, a tendência geral, que se verifica por toda a Índia, hoje em dia, no sentido de traduzir para o inglês as literaturas vernáculas. Por isso também se traduzem textos goeses do konkani edo marata para o inglês. Esse facto, relativoao papel centralizador do inglês em detrimento da tradução entre línguas vernáculas da Índia, tem causado polémica, ${ }^{6}$ mas, cada vez mais, o inglês alia o papel de língua franca dentro da Índia (a par do hindi), com a acrescida possibilidade de internacionalização, cobiçada pelos autores traduzidos.

No caso da literatura goesa, a motivação da tradução para a língua inglesa responde, na minha opinião, em primeiro lugar a um interesse local, goês, de projectar a sua herança cultural para o resto da Índia, ao mesmo tempo que se dá a conhecer essa tradição às gerações mais jovens. Por outro lado, mais de cinquenta anos depois da integração de Goa na União Indiana, o interesse pelo português renovou-se em alguns sectores da sociedade goesa, que mantêm ligações familiares com Portugal e que vê este país como uma alternativa de emigração, visto que a comunidade goesa está bem integrada nele, sobretudo em Lisboa. Em qualquer dos casos, a tradução foi fundamental para a renovação do interesse

6 Ver Mini Chandran ([s.d.]). 
pela literatura de Goa em nível nacional, dando nova circulação a uma literatura que poderia parecer condenada ou ao provincianismo (por ser a literatura de um pequeno estado) ou mesmo ao esquecimento (por ser escrita numa língua que foi proscrita em Goa, no período que se seguiu à descolonização).

Para além dos autores consagrados no século XIX, como Francisco João da Costa e Francisco Luís Gomes, que foram logo traduzidos para o inglês, prosadores do século XX, como Vimala Devi e Orlando da Costa, têm sido objecto de várias traduções. Destacaria o trabalho de tradução de Paul Melo e Castro que, para além de traduzir outros autores goeses, tem-se debruçado repetidamente sobre os contos de Vimala Devi. Quanto a Orlando da Costa, sublinharia que foram publicadas na Índia as traduções do romance O signo da ira e da peça Sem flores nem coroas, em 2016.

Poderia citar muitos exemplos mais, incluindo traduções de poesia, mas começo por referir exemplos em prosa, porque ilustram o curioso caso das repetidas referências a Moçambique na literatura de Goa em língua portuguesa. Durante o período colonial, Moçambique era uma das rotas preferenciais para a emigração de goeses e indianos, o que não só explica traços da actual sociedade moçambicana, como também ilustra uma rota de deslocação de pessoas e bens através do Oceano Índico, mapeando iniciativas locais que tiravam partido das rotas comerciais existentes. Gostaria de encerrar esta visão dos recentes desenvolvimentos no estudo da literatura goesa ilustrando a sua pertinência para os estudos do Índico, na medida em que, pela palavra escrita, os autores goeses foram documentando essas ligações entre diversas costas, onde a iniciativa privada e as prioridades na vida dos povos da região ia além do guião escrito pelas políticas coloniais. É essa outra história que ainda falta fazer.

Na antologia de contos Monção (1963), Vimala Devi inclui três narrativas sobre a emigração goesa para Moçambique: "O futuro e o passado" (pp. 71-75), “Ocaso" (pp. 53-57) e "O genro-comensal” (pp. 31-46), embora existam mais referências dispersas a Moçambique em outros contos. O detalhe importante aqui é a continuidade do tema, a presença de Moçambique nas vivências de Goa, na rotineira e partilhada referência a parentes distantes, a projectos futuros, a aspirações individuais dependentes do dinheiro que deveria chegar, vindo do outro lado do oceano. Toda uma história do Oceano Índico 
e das suas rotas e relações é aqui delineada, abrindo o horizonte para investigações futuras. Detalhe importante é também a continuidade entre as narrativas de Vimala Devi e textos dos jornais literários de Goa, em que também reaparecem referências a Moçambique. Termino com uma citação eloquente de Orlando da Costa sobre os emigrantes a bordo de um navio, em trânsito para a costa africana:

\begin{abstract}
Antes de aportar ao seu destino, lívido de enjoo permanente e perdido de solidão, Camilo assistiu ao sucessivo fundear do seu navio fantasma em Mombaça, Zanzibar e Dar-es-Salam e passar ao largo de Mocímboa da Praia, Porto Amélia e Quelimane. Quando finalmente acostou ao porto da Beira, o barco já levava menos de um terço de passageiros. Ao desembarcar em Lourenço Marques percebeu que alguns viajantes e familiares, quase descalços e sentindo-se certamente mais estrangeiros do que nunca, ainda seguiriam a sua rota, de comboio, para destinos de suor e ouro como o de Transval e Durban, tão tormentosos como promissores [...]. Se ele quisesse continuar os estudos em Portugal, que fosse para Coimbra ou Lisboa para se fazer doutor em leis; de contrário, que viesse até África experimentar a sua sorte e pôr à prova as suas capacidades [...] sem se sentir desenraizado como iria, certamente, acontecer, se preferisse ir para a metrópole, porque em Moçambique havia tantos goeses e de quase todas as castas, que o fariam em muitas circunstâncias sentir-se em casa. (COSTA, 2000, p. 140)
\end{abstract}

O mapa sociológico e a invocação histórica contidos nesse parágrafo são suficientemente eloquentes para dispensar comentário. Comprova-se também, mais uma vez, o impressionante poder da literatura para alargar a nossa visão do mundo e abrir novas janelas a uma investigação transdisciplinar na área das humanidades.

\title{
RESEARCH ON GOA IN INDIAN OCEAN STUDIES
}

\begin{abstract}
For decades, Goa either was a forgotten or a marginal subject within the field of studies addressing the revision of colonial history, in order to map the aftermath of European decolonization. However, on the transition to the $21^{\text {st }}$ century, Goa became the research object for several projects and it is becoming a more established field of studies. What have been the conclusions of research on this small but intriguing state? This article presents an overview of the state of the art concerning research on Goa, highlighting the main conclusions and the relevance of these conclusions for research on the socio-historical and cultural dynamics of the Indian Ocean. In the second place, and considering the existence of several official languages in Goa (Konkani, Marathi and English), this contribution discusses the contemporary impact of Portuguese cultural heritage and, more specifically, research on Goan literature in Portuguese.
\end{abstract}

Keywords: translation; emigration routes; historical memory and literature. 


\section{REFERÊNCIAS}

BRUGIONI, Elena; PASSOS, Joana. Narrando o Índico (Dossiê). Diacrítica - Série Estudos Literários, v. 27, n. 3, 2013.

COSTA, Orlando da. O último olhar de Manu Miranda. Lisboa: Âncora Editores, 2000.

HOFMEYR, Isabel; PEARSON, Michael Pearson; GUPTA, Pamila (Eds.). Eyes Across the Water: Navigating the Indian Ocean. Pretoria: Unisa Press, 2010.

MACHADO, Everton; BRAGA, Duarte D. (Orgs.). Goa portuguesa e pós-colonial: literatura, cultura e sociedade. Lisboa: Húmus/CEC, 2014.

MATOS, Artur Teodoro de; CUNHA, João Manuel Teles e (Eds.). Goa passado e presente. Lisboa: CEP/Universidade Católica, 2012.

MINI CHANDRAN (Shahapedia). The Practice of Translation in India. Disponível em: $<$ www.sahapedia.org/the-practice-of-translation-india $>$. Data de acesso: 12 set. 2017.

PASSOS, Joana. Literatura goesa em português nos séculos XIX e XX: perspectivas póscoloniais e revisão crítica. Ribeirão/V. N. Famalicão: Húmus/CEHUM, 2012.

PASSOS, Joana et al. Inside/Outside Lusofonia: The Case of Goa. Portuguese Literary E Cultural Studies, "Lusofonia and its Futures" (ed. João Cezar Rocha), n. 25, 2013, pp. 117-123.

PENSANDO GOA - uma peculiar bilioteca em língua portuguesa. Site do Programa homônimo. Helder Garmes (Coord.). Universidade de S. Paulo. Disponível em: <http://goa.fflch.usp.br/>. Acesso em: 9 abr. 2018.

SHETTY, Manohar (Ed.). Ferry Crossing. Gurgaon, Haryana State [Índia]: Penguin Books India, 1998. 